\title{
Ética na Pesquisa em Psicologia: Princípios, Aplicações e Contradições Normativas
}

Ethics In Research In Psychology: Principles, Applications And Normative Contradictions

Ética En La Investigación En Psicología: Principios, Aplicaciones Y Contradicciones Normativas

Livia de Oliveira

Borges, Sabrina Cavalcanti Barros \& Clara Pires do Rêgo Lobão Amorim Leite

Universidade Federal de Minas Gerais

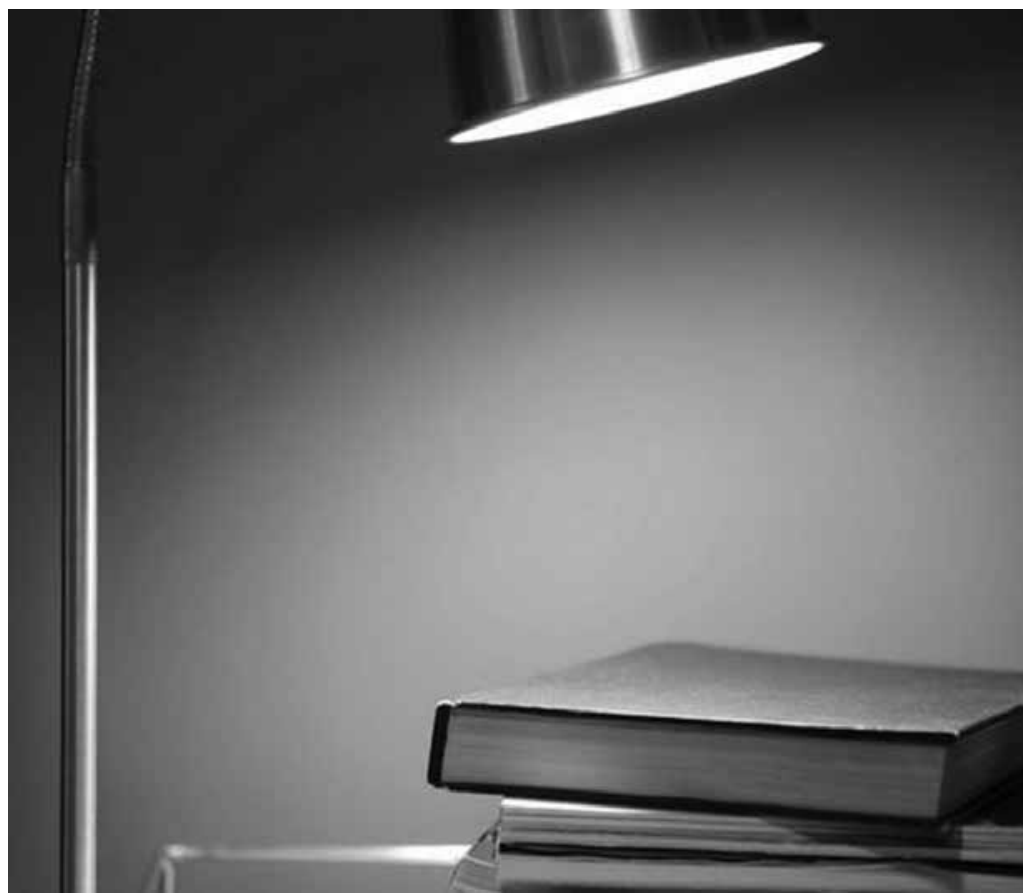


Resumo: As polêmicas entre pesquisadores sobre os princípios éticos e morais norteadores do planejamento e sobre o desenvolvimento de suas atividades com seres humanos são cada vez mais frequentes. O presente artigo foi elaborado com o objetivo de apresentar reflexões que possam contribuir para clarear as contradições dos princípios éticos defendidos pelos pesquisadores/psicólogos em referência à aplicação da Resolução CNS no 196/96, bem como em relação ao conteúdo do Projeto de Lei no 78/2006. Tenta-se apreender os significados de tais contradições no desenvolvimento da pesquisa em Psicologia. Elaborado, inicialmente, para contribuir com os debates no Fórum de Ética realizado no XIII Simpósio de Pesquisa e Intercâmbio Científico em Psicologia, promovido pela Associação Nacional de Pesquisa e Pós-Graduação em Psicologia, o texto se vale da análise interpretativa de documentos, que é confrontada com a experiência das autoras em pesquisa e com referências bibliográficas. Em síntese, o texto situa a questão da ética na pesquisa diante do quadro normativo existente no País, desenvolve a análise dos documentos normativos e sugere algumas alternativas de ação tendo em vista o aperfeiçoamento do quadro regulatório.

Palavras-chave: Ética em pesquisa científica. Pesquisa científica - Psicologia. Consentimento Livre e Esclarecido. Bioética.

\begin{abstract}
The controversies among researchers about the ethical and moral principles that guide the planning and the development of their activities with human beings have become more frequent. This article was elaborated with the objective of presenting reflections that might contribute to enlighten the contradictions of the ethical principles supported by psychologist researchers and which are related to the application of CNS Resolution $n^{0} \mathbf{1 9 6 / 9 6}$ and to the content of Law Project $n \underline{0}$ 78/2006. This is an attempt to understand the meanings of such contradictions in the development of psychological research. The text was developed initially to contribute with the discussions of the Forum on Ethics held at the XIII Symposium of Research and Scientific Exchange in Psychology, sponsored by the National Association for Research and Graduate Studies in Psychology, and it consists in an interpretative analysis of documents, compared with the research experience of one of the authors and the review of literature. In short, the text deals with the question of ethics in research in relation to the norms set in the country, develops the analysis of institutional documents and suggests some alternatives of action aimed at improving the regulatory framework.
\end{abstract}

Keywords: Ethics in research. Ethic Research with human beings. Scientific research - psychology. Informed consent. Bioethics.

Resumen: Las polémicas entre los investigadores sobre los principios éticos y morales guías de la planificación y sobre el desarrollo de sus actividades con seres humanos son cada vez más frecuentes. El presente artículo fue elaborado con el objetivo de presentar reflexiones que puedan contribuir para aclarar las contradicciones de los principios éticos defendidos por los investigadores/psicólogos en referencia a la aplicación de la Resolución CNS 196/96 así como con relación al contenido del Proyecto de Ley 78/2006. Se intenta abarcar los significados de tales contradicciones en el desarrollo de la investigación en Psicología. Elaborado, inicialmente, para contribuir con los debates en el Foro de Ética realizado en el XIII Simposio de Investigación e Intercambio Científico en Psicología, promocionado por la Asociación Nacional de investigación y Posgrado en Psicología, el texto se vale del análisis interpretativo de documentos, que es confrontada con la experiencia de las autoras en investigación y con referencias bibliográficas. En síntesis, el texto sitúa la cuestión de la ética en la investigación ante el cuadro normativo existente en el País, desarrolla el análisis de los documentos normativos y sugiere algunas alternativas de acción teniendo en vista el perfeccionamiento del cuadro regulatorio.

Palabras clave: Ética en investigación. Investigación con seres humanos. Investigación científica - Psicología. Consentimiento informado. Bioética.

Os debates, as dúvidas e as divergências entre pesquisadores sobre princípios éticos e morais que norteiam o planejamento e o desenvolvimento de suas atividades, bem como as críticas de setores da sociedade a procedimentos adotados no campo científico, não são novidades. No Brasil, esses debates vêm crescendo paulatina e concomitantemente à ampliação da comunidade científica/acadêmica. Muito mais tarde que os países mais desenvolvidos, só a partir da década de 90 se tomou consciência de que a aplicação dos referidos princípios não podia ser resolvida exclusivamente em âmbito individual pelo pesquisador. Tal tomada de consciência concretizouse na edição da Resolução no 196, do Conselho Nacional de Saúde (CNS, 1996), que normatiza a realização de pesquisas que envolvem seres humanos no Brasil (Bucher- 
Maluschke, 2006). O fato representa um avanço no sentido de estabelecer um controle social sobre as atividades de pesquisa, o que é plenamente legitimado pela própria história do desenvolvimento científico (Koller, 2008; Secretaria Municipal de Saúde de São Paulo, 2007). Essa resolução, uma primeira tentativa de normatização, tem gerado também muitas polêmicas no meio acadêmico da Psicologia (Fórum de Ética em Pesquisa da ANPEPP1', 2012; Leitão, 2010), a exemplo de outros ambientes acadêmicos, como a área de saúde coletiva (Guerriero, 2008; Minayo, 2008; Ribeiro, 2005; Schimdt, 2008a, 2008b). Como todo debate motiva e influencia as atividades reflexivas das pessoas, já se encontram publicações sobre o assunto (por exemplo, Bucher-Maluschke, 2006; Monteiro, 2007; Silva \& Grubits, 2006), mas, enquanto floresce na produção bibliográfica, tal debate tem feito parte do cotidiano de psicólogos/pesquisadores. Ele tem sido acalorado, reabastecido e tem se renovado continuamente por diversas ocorrências (encontros e desencontros) no relacionamento dos pesquisadores (especialmente professores e pós-graduandos) com os diversos comitês de ética em pesquisa (CEPs) estabelecidos nos termos da citada resolução, e com editores das revistas científicas no País, bem como pelo trâmite de projetos de lei no Congresso Nacional. Um desses projetos era o PL no 2.473/2003 (http://www.ghente.org/ doc_juridicos/pl2473.htm), de autoria do Deputado Federal baiano Colbert Martins, que, em síntese, propunha que a resolução do CNS fosse transformada em lei. Tal projeto, no entanto, foi arquivado em $1^{\circ}$ de fevereiro de 2011 (http://www.camara.gov.br/ proposicoesWeb/fichadetramitacao?idPropos icao=142406); tramita atualmente o Projeto de Lei no 78/2006, de autoria do Senador Cristovam Buarque. Segundo informe público no Portal de Atividade Legislativa (do Senado Federal), ele se encontra desde 13 de agosto de 2012 na Comissão de Ciência, Tecnologia, Inovação, Comunicação e Informática. No seu quinto artigo, define a Comissão Nacional de Ética em Pesquisa (CONEP) como o órgão máximo responsável por acompanhar e avaliar todas as pesquisas no território nacional e aplicar as sanções administrativas previstas no PL. Sua aprovação significará que o seu descumprimento adquire o sentido de crime, pois prevê penas de detenção e multas em caso de desenvolvimento de pesquisa em desacordo com o Termo de Consentimento ${ }^{2}$ ou com o protocolo aprovado pelo CONEP.

Ambos os projetos de lei mencionados têm provocado polêmicas e preocupações em setores da sociedade e motivado ações, como a audiência pública realizada pela Comissão de Ciência e Tecnologia, quando ainda tramitava o primeiro PL. O Jornal da Ciência, de 16 de abril de 2010, sobre os resultados de tal audiência, relata:

O PL no 2.473/2003, que regulamenta estudos clínicos com seres humanos, é discutido em audiência pública na Câmara dos Deputados, e deve ser revisto.

O Projeto de Lei no 2.473/2003, que regulamenta a realização de pesquisas com seres humanos, foi debatido na terça-feira (13/4) em audiência pública na Câmara. Segundo a relatora do projeto, Deputada Cida Diogo (PT-RJ), o texto deverá ser revisto e seguir o trâmite com um substitutivo.

Para a Deputada, o PL original, proposto por Colbert Martins (PPS-BA), é muito detalhista, e, por isso, deve ser simplificado para poder ser aplicado em longo prazo e não engessar as pesquisas. Além disso, a petista defende a retirada de punições do texto.

Martins acredita que as pesquisas que envolvam seres humanos só devem ser admissíveis quando oferecerem possibilidade de gerar conhecimento para entender, prevenir ou aliviar um problema que afete o bem-estar.

No texto entregue à Câmara em 2003, o deputado define conceitos, regulamenta a atividade e chega a tipificar crimes, sem prejuízo a sanções previstas no Código Penal e em leis especiais: 'Nós temos condições de construir uma alternativa que concilie os dois projetos, para que o País 
possa avançar', disse Cida Diogo durante a audiência (Jornal da Ciência, no 664, de 16 abril, 2010. http://www.jornaldaciencia. org.br/Detalhe.jsp?id=70323)

Os resultados da audiência pública, a tramitação do projeto de lei de autoria do Senador Cristovam Buarque e o papel atribuído pelo PL à CONEP sinalizam que há possibilidades de negociação no sentido de o PL e as resoluções da CONEP serem ajustadas de maneira a atender à compreensão de ética dos vários segmentos acadêmicos que realizam pesquisas com seres humanos. É, portanto, salutar vislumbrar que há possibilidades de as normas éticas terem em conta as especificidades da Psicologia, ou até de se instituírem normas específicas.

Os citados resultados da audiência pública também sinalizam que as preocupações e as divergências em torno dos meios de estabelecer o controle social na pesquisa já extrapolavam o ambiente acadêmico/ científico e atingiam o ambiente sociopolítico brasileiro. Dallari (2008) reconhece o interesse de garantir direitos individuais que guia a Resolução no 196/96, mas defende a necessidade de compatibilizar tais interesses aos societários de incentivar o desenvolvimento científico e tecnológico visando ao bem-estar coletivo.

Esse contexto de incômodos e inquietações incentiva a elaboração de indagações como: que sistema ético fundamenta a resolução que serviu de ponto de partida para todo esse debate? Que incômodos dos pesquisadores/ psicólogos têm sustentado tal debate? Que querem os psicólogos/pesquisadores de suas atividades? São contrários a quaisquer éticas? São contra uma ética específica? Reagem a quaisquer controles por parte da sociedade? Estão contra as normas? Estão simplesmente reagindo ao novo?
Tendo em vista indagações como essas, o presente texto foi redigido com o objetivo de apresentar reflexões que possam contribuir para clarear as contradições existentes entre os princípios éticos ${ }^{3}$ defendidos pelos pesquisadores/psicólogos em relação à aplicação da Resolução CNS no 196/96, na tentativa de apreender os significados de tais contradições no desenvolvimento da pesquisa em Psicologia.

As reflexões que serão aqui apresentadas resultaram exclusivamente da análise de alguns documentos sobre o assunto (o Projeto de Lei em trâmite, a Resolução, algumas notícias, etc.) e seu confronto com a experiência cotidiana de uma das autoras como professora-pesquisadora, em sua convivência com os colegas no meio acadêmico e com alguma literatura especializada na área. Várias dessas reflexões consistem muito mais em indagar e pôr em dúvida do que em construir respostas conclusivas.

\section{A ética e as normas morais}

Partindo, então, da primeira indagação levantada - que sistema ético fundamenta a resolução que serviu de ponto de partida para todo esse debate? - é preciso lembrar que a Resolução CNS no 196/96 inicia, no seu preâmbulo, evocando os documentos internacionais e nacionais que fundamentaram a sua elaboração. No preâmbulo da resolução, estão também explícitos quais seriam os princípios éticos que lhe servem de norte, no seguinte trecho:

Essa Resolução incorpora, sob a ótica do indivíduo e das coletividades, os quatro referenciais básicos da bioética: autonomia, não maleficência, beneficência e justiça, entre outros, e visa a assegurar os direitos e deveres que dizem respeito à comunidade científica, aos sujeitos da pesquisa e ao Estado (Resolução CNS no 196/96. Preâmbulo) 
Esclarece-se que o ponto de partida das reflexões é a definição de La Taille, que afirma que os princípios éticos devem permitir que as pessoas respondam à pergunta: "que vida eu quero viver?" (2006, p.

36).
Ficam assim explícitos alguns princípios éticos. Assinala-se aqui, entretanto, que a expressão entre outros pode ser interpretada como indicador de que a referida resolução está partindo do pressuposto de que não é necessário deixar claro o sistema completo de princípios éticos norteadores. Em parte, tal opção é aceitável, considerando que o objetivo da resolução é preservar os direitos individuais dos sujeitos participantes de pesquisa, e não a atividade de pesquisa como um todo. De qualquer forma, compete indagar: seriam esses quatro princípios éticos mencionados para os psicólogos/ pesquisadores fundamentais? Para se ter certeza disso, antes seria preciso elucidar o que seria uma ética. Tal discussão ultrapassa, entretanto, o escopo deste texto. Esclarecese que o ponto de partida das reflexões é a definição de La Taille, que afirma que os princípios éticos devem permitir que as pessoas respondam à pergunta: "que vida eu quero viver?" (2006, p. 36). A ética define o que seja uma vida boa; permite distinguir o bem e o mal. Aplicando-se essa definição à atividade de pesquisa, uma ética em pesquisa deveria consistir em um conjunto de princípios de valor que permitisse responder: que pesquisa se quer realizar? Deveria permitir identificar o que é uma boa pesquisa. Dizer, então, que a pesquisa deve assegurar aos participantes (sujeitos de pesquisa) autonomia, não maleficência, beneficência e justiça está em conformidade com o que se concebe que uma pesquisa deva ser ou deva representar? A resposta pode ser que seguramente estão em conformidade. Para a maioria dos psicólogos/pesquisadores, o acesso ao próprio objeto de pesquisa não é nada simples, e, por isso, a relação empática com os participantes é uma questão simultaneamente de valor e de técnica. Para estabelecer tal relação, é necessário valorizar não só os princípios já citados mas também a importância de os participantes se sentirem bem, livres para opinar, além de sentirem que a relação com o pesquisador não os ameaça nas suas relações cotidianas. Portanto, além de autônomos para decidir se participam ou não, os participantes precisam sentir-se seguros para exercer sua autenticidade. O compromisso com os princípios da não maleficência, da beneficência e da justiça constitui um norteador importante para evitar as atrocidades praticadas na contemporaneidade contra as pessoas em nome da ciência e do progresso, atrocidades que estão registradas na história da ciência e às quais aqueles que se ocupam de temas referentes à ética estão sempre voltando (Menegon, 2006; Monteiro, 2007; Padilha, Ramos, Borenstein, \& Martins, 2005), o que nos dispensa de fazer o mesmo aqui. $\mathrm{O}$ princípio da autonomia do participante, por sua vez, tenta evitar que ele seja submetido a atrocidades, violências, abusos e a outras práticas, admitindo-se que o relacionamento com o pesquisador seja também uma relação de poder, na qual eventualmente o participante possa ser coagido a submeter-se a tais atos. Esses princípios se relacionam a uma série de outros princípios (valores éticos) que, para os psicólogos/pesquisadores, são igualmente importantes, alguns deles em decorrência do próprio objeto de pesquisa da Psicologia, que pode ser definido sinteticamente como os aspectos psicológicos da vida das pessoas. Os psicólogos também acreditam que, para garantir os princípios já citados, é preciso ter em vista princípios como o compromisso com a qualidade do que fazem, com o acolhimento dos outros (em seus sentimentos, afetos e cognições), etc. Para Schmidt, na Psicologia, "a autorreflexão e o autêntico respeito pela alteridade formam como que um território no qual a pesquisa se instala e acontece" (2008a, p. 48). Portanto, para a autora, os princípios éticos não são aspectos a serem garantidos pelos procedimentos burocráticos dos CEPs ou pelo uso do TCLE, mas elementos intrínsecos ao processo de desenvolvimento das pesquisas em ciências humanas, principalmente daquelas que adotam metodologias que pressupõem maior 
proximidade e/ou envolvimento entre o pesquisador e os pesquisados.

La Taille (2010) desenvolveu argumentos no sentido de que os princípios de dignidade e liberdade deveriam ser os norteadores priorizados na condução das pesquisas. O primeiro - dignidade - refere-se ao direito à integridade física e psicológica e ao respeito moral por parte de outrem, e o segundo liberdade - o direito de não ser coagido por outrem, nem de coagir as demais pessoas. Para o autor, esses dois princípios são suficientemente abrangentes e mais claros do que aqueles citados no preâmbulo da Resolução no 196/96.

Schramm, Palácios e Rego (2008), por sua vez, indagam se há possibilidade de os princípios já definidos darem conta das características e das demandas das diversas regiões, populações e da diversidade humana. Ao mesmo tempo, lembram que a Resolução não impede a inclusão de novos princípios morais. Propõem, então, que seja adotado o princípio da proteção aos sujeitos participantes, ressaltando a necessidade de aplicá-lo às situações em que esses sujeitos não têm condições de apresentar efetivamente um consentimento livre e esclarecido.

Obviamente, não se seguirá levantando numerosos princípios, mas a intenção é deixar claro que os princípios mencionados na Resolução CNS no 196/96 devem estar em consonância com uma constelação de outros princípios éticos e que, em boa parte das pesquisas realizadas no campo da Psicologia, as atitudes e as condutas do pesquisador frente aos participantes representam a concretização de seus princípios éticos e, simultaneamente, das técnicas adotadas na tentativa de construir o acesso ao seu objeto de estudo, acesso esse, diga-se de passagem, bastante polemizado nas discussões epistemológicas no campo da Psicologia.
Esses aspectos não põem, portanto, a Resolução CNS no 196/96 em contradição com as definições éticas dos psicólogos, pois os princípios de valor ali evocados não contradizem, em tese, os demais princípios de valor dos psicólogos. Mas assinala-se que nem os PLs, nem a resolução mencionam no seu texto tais princípios éticos. Depois da aprovação da lei, o que tenderá a servir comumente de parâmetro para avaliar a adequação do planejamento e do desenvolvimento das pesquisas e/ou para a tomada de decisões nos CEPs (e/ou perante o Poder Judiciário) será o corpo do texto da lei, e não as intenções com que foi elaborada.

A citada resolução se detém, então, a normatizar como tais princípios deveriam ser postos em prática. Nesse sentido, indagase se de fato estão abordando uma ética. La Talle, o mesmo autor que brindou seus leitores com aquela definição do que seja uma ética, diferencia o plano ético do moral. E afirma que a moral deve orientar as pessoas a responder "como devo agir?" (2006, p. 31). Assim, diferentemente da ética, a moral deve oferecer normas de conduta, e é nesse plano que o documento se desenvolve, portanto, tem um caráter mais moralizador do que ético. Esse fato, entretanto, não diminui a importância da normatização moral, pois não existe uma ética isolada da noção de obrigatoriedade social. O senso de dever é necessário para um convívio social salutar. Os dois planos - ético e moral - se relacionam dialeticamente, e um afeta o significado do outro. O plano ético fundamenta o plano moral, e este último permite que o plano ético se concretize. Para que as pessoas possam incorporar o plano moral em profundidade, precisam ser capazes de refletir como ele se relaciona com o plano ético. Cumprir uma moralidade simplesmente porque está normatizada, estabelecida socialmente ou por normas formais é um empobrecimento do senso crítico e um esvaziamento da própria autonomia. Devem-se identificar 
os princípios éticos que estão por trás da norma moral e cumprir a moralidade porque se adotou como seus os princípios éticos de sua sustentação (La Taille, 2006; Rios, 2006). Pode-se esperar que o pesquisador sem uma consciência ética (que valorize sua própria autonomia) seja capaz de proteger a autonomia do outro, a autonomia do sujeito participante da pesquisa? A norma moral sobre a pesquisa que envolve seres humanos que não explicita a ética que a fundamenta norteará os CEPs adequadamente?

Deve, entretanto, ficar claro, de antemão, que as polêmicas que se desenvolvem e persistem no meio acadêmico, motivadas pela resolução e pelo projeto de lei citados, não duvidam centralmente da necessidade de uma ética, nem partem necessariamente de uma divergência ética, mas focalizamse, em realidade, sobre que conjunto de normas morais seria coerente com o sistema ético predominantemente assumido pelos psicólogos/pesquisadores.

A Resolução no 196/96, no segundo item dedicado aos objetivos e fundamentos, apresenta conceitos básicos que nortearam o âmbito de sua aplicação; assim, define pesquisa como a "classe de atividades cujo objetivo é desenvolver ou contribuir para o conhecimento generalizável". Ora, tal conceito, na atualidade, representa não só na Psicologia mas também nas ciências humanas, apenas uma das visões epistemológicas de ciência, e não toda a atividade científica e de pesquisa (Guerriero, 2006; Guerriero \& Dallari, 2008; Minayo, 2008). A definição, portanto, põe em dúvida o próprio âmbito das normas. Destina-se mesmo a todas as pesquisas com seres humanos ou apenas a uma modalidade de pesquisa com seres humanos? Recorrendose, então, à justificativa do PL em trâmite, constata-se que o seu autor desenvolve seus argumentos dirigindo-os à pesquisa biomédica. Por que, então, elabora o PL generalizando sua aplicação ao conjunto total de pesquisa com os seres humanos?

Seguindo na justificativa, o autor desenvolve sua argumentação exemplificando com uma pesquisa sobre malária com moradores de comunidades ribeirinhas como cobaias humanas no Estado do Amapá, mas o fato é que deixa novamente a dúvida sobre qual o âmbito de aplicação das normas. Tanto a definição da pesquisa quanto a justificativa do PL levam a questionar se não há uma sobregeneralização, quando se referem à pesquisa com seres humanos. O objeto não seria apenas as pesquisas que abrangem aspectos biológicos, com método experimental? Tal restrição de alcance não seria estranha, considerando de qual órgão (o CNS) partiu a iniciativa de criar normas morais para o desenvolvimento de pesquisas. Voltando ao texto da Resolução no 196/96, observa-se que adiante esta descreve mais detidamente como devem ser as pesquisas com seres humanos. Parte de seu terceiro item estabelece que:

III.3 - A pesquisa em qualquer área do conhecimento envolvendo seres humanos deverá observar as seguintes exigências: a) ser adequada aos princípios científicos que a justifiquem e com possibilidades concretas de responder a incertezas; b) estar fundamentada na experimentação prévia realizada em laboratórios, animais ou em outros fatos científicos; [...]

A leitura desse trecho leva novamente a perguntar: quando da elaboração de tal projeto, em que tipo de pesquisa se estava pensando? Pesquisas, por exemplo, sobre valores, crenças e opiniões das pessoas, sobre condutas de amizades entre adolescentes ou sobre o exercício da liderança em instituições estariam contempladas aí? Pesquisas com esses temas poderiam partir de experimentação prévia com animais? Ainda sobre o âmbito de aplicação das normas, a citada resolução, no item VIII.5, 
exige que a CONEP submeta ao Conselho Nacional de Saúde suas propostas de normas gerais aplicadas às pesquisas com seres humanos bem como seu plano e relatório de trabalho anual. Compete, então, indagar: por que pesquisas com seres humanos, que, em tese, podem abarcar, por exemplo, temas sobre o engajamento de pessoas de baixa instrução em partidos políticos, sobre as crenças das pessoas sobre as religióes, sobre a discriminação racial, sobre comportamentos de consumo, sobre as formas adotadas pelas famílias para gerenciarem a economia doméstica, sobre práticas sociais de adoção de filhos, etc., devem submeter-se ao Conselho Nacional de Saúde? Por que o Conselho Nacional de Saúde deveria preocupar-se com todas as pesquisas que envolvem seres humanos?

Em síntese, com esses aspectos analisados, espera-se ter identificado adequadamente os pontos do documento que estão relacionados às dúvidas sobre a aplicação das normas, reconhecendo-se haver contradição entre identificar o conjunto de normas como destinado à pesquisa com seres humanos e os conteúdos do detalhamento das normas. As experiências dos psicólogos/ pesquisadores é que tal contradição tem tido desdobramentos na convivência com os CEPs (Trindade \& Szymanski, 2008). Um deles é o fato de se exigir que pesquisas que não são experimentais sejam descritas como se o fossem, o que leva os pesquisadores a tratar tais normas com mero formalismo. Na Psicologia, são frequentes as pesquisas classificadas como exploratórias em decorrência do estado de desenvolvimento científico sobre determinados assuntos ou em decorrência de novos olhares para temas tradicionais. Pesquisas exploratórias têm também um lugar importante na ciência, e não é por acaso que algumas publicações sobre metodologia (Goulart, 2002; Piovesan \& Temporini, 1995; Tripodi, 1975; Wainer, 2000) identificam e descrevem tal tipo de pesquisa. Destacam, inclusive, o potencial inovador desse tipo de pesquisa. Nele, na maioria das vezes, não é tecnicamente adequado formular hipóteses, haja vista que não há uma teoria sólida que lhe ofereça sustentação; no entanto, a Resolução CNS no 196/96, no seu item VI.2, letra a, exige que sejam apresentadas. Os que reconhecem a obrigatoriedade (dever moral) de submeter os projetos aos CEPs são, portanto, obrigados a explicitar as hipóteses, porém estas são escritas de forma mais semelhante a opiniões de senso comum. Obviamente, não as repetem na hora de encaminhar as publicações ou de submeter os projetos a outras instâncias distintas dos CEPs. Esse tipo de desdobramento foi descrito por Padilha et al. (2005) no campo das pesquisas da Enfermagem, e esses autores denominaram o processo banalização da ética, que termina por deixar de lado questões mais relevantes na definição da pesquisa que se quer realizar em função de reduzir o que seja ética ao cumprimento da resolução referida. Em outras palavras, a crítica de Padilha et al. envolve a denúncia que os pesquisadores têm repetido procedimentos morais sem se indagar sobre os princípios éticos que estão por trás e que os justificariam.

Um segundo desdobramento é o entendimento de alguns pesquisadores das áreas de ciências humanas e sociais de que a Resolução no 196/96, tendo a autoria do CNS, só se aplica a pesquisas que possam ser incluídas no campo da saúde e que, em consequência, não submetem seus projetos aos CEPs. Os psicólogos/pesquisadores se percebem vivendo situações não equitativas, principalmente quando se comparam com os pesquisadores de outros campos das ciências humanas e sociais aplicadas. A Psicologia abrange áreas clínicas e/ou de saúde e experimentais, e por isso exige o envolvimento dos psicólogos/pesquisadores com mais frequência no dever moral de submeter suas pesquisas aos CEPs, fato que problematiza o aspecto da equidade. $\mathrm{O}$ 
segmento que reclama essa falta de equidade é aquele que, na consulta desenvolvida pela Comissão de Ética da ANPEPP (Trindade \& Szymanski, 2008), considerava que o controle das pesquisas pelo sistema CEPs/CONEP representa uma forma de subordinação do campo da Psicologia ao de cunho biomédico.

Um terceiro desdobramento da falta de clareza do âmbito de aplicação é tornar difícil o posicionamento dos editores de revistas científicas, pois raras revistas publicam exclusivamente pesquisas clínicas, de saúde e/ou com método experimental. Além disso, parte do que os psicólogos/pesquisadores publicam tanto se enquadra na linha editorial de revistas da Psicologia quanto no de outros campos de interface. Se revistas da Psicologia estão exigindo a comprovação de aprovação dos CEPs, há psicólogos/pesquisadores que passaram a decidir a que revista submeter seus artigos conforme a exigência ou não da referida comprovação. Essa realidade pode significar certo esvaziamento de tais revistas e/ou o atraso do seu desenvolvimento, embora as revistas da Psicologia sejam hoje bem estruturadas e avaliadas como resultado de anos de dedicação dos editores, do empenho das entidades científicas, das instituições de fomento em pesquisa e da comunidade acadêmica como um todo. Gestões subsequentes da ANPEPP têm agido em defesa dos pesquisadores que enfrentam dificuldades diante dos editores pelas exigências de apresentar documentos emitidos pelos CEPs. Apesar disso, as divergências entre editores persistem, conforme atesta o relatório do fórum de ética do último Simpósio de Pesquisa e Intercâmbio Científico (Fórum de Ética em Pesquisa da ANPEPP, 2012).

Mas, apesar de todas essas considerações e reiterando o que se assinalou sobre as polêmicas acerca da resolução do CNS e do PL não terem como pilar básico divergências a respeito do sistema ético, registra-se o reconhecimento do mérito em institucionalizar o controle social da ética em pesquisa e barrar a instrumentalização de brasileiros em pesquisas que não seriam aprovadas em países que já têm uma tradição consolidada no assunto (Calvetti, Fighera, \& Muller, 2008; Monteiro, 2007). E, mais que isso, há uma tendência entre os psicólogos/ pesquisadores em reconhecer a necessidade do controle social para garantir que os princípios éticos sejam concretizados nas atividades. Compreende-se a pesquisa como uma prática social.

O problema de definição do âmbito tem, ainda, relação com outras contradições vivenciadas pelos psicólogos/pesquisadores diante das normas em vigor. Assim, voltando ao item III.3, do qual se citou uma parte anteriormente, assinala-se que, na letra $g$, se estabelece que a pesquisa deve "contar com o consentimento livre e esclarecido (TCLE) do sujeito da pesquisa e/ou seu representante legal". Tal exigência normativa tem por intenção preservar a autonomia do participante. Mas será que esse procedimento atinge seu objetivo em quaisquer tipos de pesquisa com seres humanos? Em boa parte das pesquisas, sim. Naquelas com medicamentos, exemplificadas na justificativa do autor do PL em trâmite, seguramente é um procedimento adequado. Da mesma maneira, provavelmente adapta-se a maior parte (senão a todas) das pesquisas cuja fundamentação epistêmica se origina do positivismo ou do neopositivismo (Guerriero \& Dallari, 2008). Essas pesquisas não são obviamente a totalidade do que é desenvolvido na atualidade. O enquadramento do TCLE a um modelo tradicional de pesquisa (positivista e/ou experimental) parte do pressuposto que o consentimento informado se realiza em um momento pontual do processo de coletar dados. Em pesquisas que adotam um referencial interpretativo da Psicologia crítica e/ou que adotam métodos como as pesquisas participantes, o real consentimento informado 
é construído e reconstruído processualmente ao longo do desenvolvimento da pesquisa (Guerriero \& Dallari, 2008; Mueller \& Instone, 2008; Schmidt, 2008b). A diversidade de pesquisa, refletindo os diferentes paradigmas subjacentes, precisa ser aceita e incluída na reflexão ética (Guerriero, 2008). Adicionalmente, considera-se que os argumentos de Guerriero e Dallari terminam por sublinhar a contradição entre garantir a autonomia dos sujeitos em poder interromper a participação a qualquer momento e assinar um termo formal no início do processo. Aguirre (2008) registra, também, casos em que o TCLE não funciona como deveria, haja vista que participantes podem assinálo, porém o tratam como uma burocracia sem sentido ou sem anteceder a assinatura do TCLE por uma efetiva compreensão da pesquisa. A autora relata casos em que pessoas que haviam assinado o TCLE desconheciam aspectos importantes da pesquisa e outras até não sabiam que estavam participando de uma pesquisa.

Além disso, indaga-se se o TCLE cumpre o papel previsto de preservação do princípio de autonomia dos participantes em todas as pesquisas, independentemente do foco temático. Por exemplo, é adequado seu uso em entrevistas com adolescentes sobre o uso ilegal de drogas? Ou será que quem defende tais normas morais acredita que as pesquisas sobre tal assunto não devam ser realizadas? Isso não constituiria a negação de uma realidade vivida muito próxima a cada um de nós? Há de se considerar que pesquisas como essas têm, por exemplo, o potencial de contribuir para a delimitação de políticas públicas no combate ao uso de drogas ilícitas bem como para desenvolver técnicas adequadas à reabilitação desses adolescentes. E não é ético planejar uma pesquisa definindo-a na direção de contribuir para a diminuição do uso de drogas ilícitas ou de suas consequências?
Para apresentar mais exemplos e evitar ficar com o viés do tema que envolve condutas consideradas ilegais, indaga-se também: o TCLE seria adequado, no caso de se entrevistar trabalhadores sobre as relações de trabalho no ambiente das organizações? Em temas como esses, da Psicologia do trabalho e das organizações, tradicionalmente, os psicólogos/ pesquisadores, por seus compromissos éticos de proteger os participantes, adotam o procedimento de não identificar os participantes. A não identificação e a assinatura do TCLE, nesses casos, são contraditórias. Membros de CEPs têm argumentado que, para superar essa contradição, basta que o TCLE esteja separado do questionário que o indivíduo responderá. A prática em pesquisa tem, no entanto, revelado que aqueles que se encontram no contexto do emprego não se sentem seguros para expor seus pontos de vista se assinam o TCLE, pois entendem que estão se identificando. É pouco provável que, em situação de mercado de trabalho tão competitivo como o que se vive atualmente, as pessoas nutram tal entendimento. Quem acredita que o TCLE operacionaliza adequadamente a garantia de autonomia ao participante provavelmente não considerou que temas como esses são atravessados pelas relações complexas de poder das organizações contemporâneas.

Exemplificando mais detidamente para tornar o argumento mais compreensível, relata-se que, em uma pesquisa em que petroleiros eram sujeitos-participantes, o comitê de ética não dispensou o TCLE, sob $\mathrm{o}$ argumento que os petroleiros da pesquisa tinham estabilidade no emprego. Entretanto, a não identificação era valorizada por aqueles petroleiros, porque independentemente da estabilidade legal, sentiam-se ameaçados por outras especificidades da gestão que lhes podia aplicar outros tipos de penalidades, como transferências indesejadas, mudanças nas tarefas, na organização dos dias de trabalho e de folga, etc, além do fato de 
aquela categoria ocupacional ter uma história em que, a despeito da estabilidade legal do emprego, colegas passaram pelo constrangimento da demissão e demoraram a recuperar o emprego, tendo que enfrentar desgastante processo judicial. Aquele CEP, provavelmente, não atentou suficientemente para as peculiaridades das relações de trabalho e exigiu o TCLE. A pesquisa foi realizada sem a aprovação do CEP, mas os seus resultados nunca foram encaminhados a qualquer revista científica. Foi publicado exclusivamente na forma de livro (Borges \& Barbosa, 2006); o papel social transformador da pesquisa, porém, é reconhecido, pois, diante dos resultados, a negociação trabalhista entre empresa e sindicato conduziu a mudança concreta nas condições de trabalho. Para as autoras, esse aspecto traduz melhor um compromisso ético do que a formalidade de um TCLE. Tal pesquisa, entretanto, não poderia ter sido realizada se o que estivesse vigorando não fosse uma Resolução do CNS, mas uma lei federal.

No capítulo do método de uma tese sobre violência no trabalho como estratégia de gestão, sua autora relata que a amostra não foi maior em decorrência da necessidade de o participante assinar o TCLE (Amazarray, 2010). O caso dessa tese não é isolado. A mesma situação se repete em quase todas as pesquisas em que o emprego é o contexto ou o objeto de estudo. Apenas não cabe aqui sair listando numerosos exemplos.

Em casos como esses, o psicólogo/pesquisador precisa contar com a adesão à pesquisa do participante de forma autônoma, autêntica e da maneira mais espontânea possível, tanto pelo compromisso com tais princípios éticos quanto pelo fato de a ausência dessas atitudes dos participantes fragilizar a consistência dos resultados. Por isso, a proteção do participante por meio da não identificação é uma necessidade ética e, ao mesmo tempo, técnica. O TCLE vem, nesses casos, então, funcionar como um impeditivo ético e técnico. Falta, certamente, em tais situações, uma reflexão mais ética e menos moral sobre o papel do TCLE.

Retomando o que já se comentou, é bom lembrar que, nos termos do PL em trâmite, as ações que estejam em desacordo com o protocolo ou com o TCLE aprovado nos CEPs serão consideradas crimes e passíveis de aplicação de pena de detenção. Assim, o PL, se aprovado como lei, promoverá a aplicação de uma moralidade que se cindiu da ética que o sustenta, e levará a uma aplicação do TCLE porque é crime não aplicá-lo, mas não porque o TCLE proteja a autonomia do sujeito. Em outras palavras, abandona-se a finalidade do bem e preserva-se o procedimento, cujo sentido era construir o caminho que levava a aquela finalidade.

Além dos desdobramentos dessa contradição, já expostos pelos exemplos utilizados, há outros referentes ao que é previsto para o conteúdo do TCLE. A Resolução no 196/96 discrimina minuciosamente o que deve ser especificado no TCLE. No seu item IV.1, letra $h$, exige que se informe "as formas de ressarcimento das despesas decorrentes da participação na pesquisa". Há de se considerar que, em pesquisas em que a participação dos sujeitos consiste no preenchimento de questionário ou em conceder entrevista, registrar tal conteúdo no TCLE passa a ser mais uma formalidade, que pode contribuir inclusive para a prolixidade do documento e para dificultar a compreensão do participante em relação aos aspectos efetivamente centrais da pesquisa. Ora, se a norma estabelece a obrigatoriedade de ressarcimento de despesas do participante e a indenização de danos, isso ocorrerá independentemente de estar escrito no TCLE; além disso, é redundante em relação ao Código Civil brasileiro, segundo o qual os cidadãos têm tais obrigações de indenização e de ressarcimento 
independentes da situação de pesquisa. Esse desdobramento configura, portanto, o excesso de detalhamento da Resolução CNS no 196/96. Corroborando, Monteiro, em sua análise aos TCLEs aplicados em Psicologia hospitalar, sustenta que precisam ser aperfeiçoados, pois "os pesquisadores têm dificuldade em elaborar um Termo de Consentimento simples e que, ao mesmo tempo, contemple todas as informações pertinentes a sua finalidade" (2007, p. 88).

Na mesma linha de excessivo detalhamento, assinala-se que a resolução em tela, nos itens $\mathrm{VI}$, lista todos os documentos que devem compor o protocolo de pesquisa, bem como detalha tudo o que a descrição da pesquisa deve abranger. No item VI.2, letra j, inclui, por exemplo, o orçamento financeiro detalhado da pesquisa. Ora, não só em Psicologia mas também em ciências humanas e entre pós-graduandos, várias pesquisas são realizadas com recursos (reprografia, papel, computador, material de expediente em geral) dos próprios pesquisadores ou com parte do material de expediente do próprio departamento do professor-pesquisador. A exigência padronizada do orçamento faz pesquisadores repetirem orçamentos totalmente artificiais, às vezes até copiados de outros projetos.

Da mesma maneira, exige-se um termo de compromisso do pesquisador responsável e da instituição de cumprir os termos da lei. A lei exige cumprimento incondicional, portanto, tal termo é absolutamente redundante. O excesso de detalhamento tende a ser visto pelos psicólogos-pesquisadores como uma burocratização da ciência, que os leva a vivenciar um conflito entre desenvolver-se como pesquisador, inovando ou aprofundando-se no seu objeto de estudo, ou tornar-se um expert em preparação de processos. Os proponentes da citada resolução aparentemente desconheciam a realidade de trabalho dos pesquisadores; são, em sua maior parte, professores universitários, e não contam com auxiliares administrativos. Seus auxiliares são, quase na totalidade, estudantes de iniciação científica e de pósgraduação que ali estão para aprender os métodos e as técnicas de pesquisa, bem como os quadros teóricos referentes a seus objetos de estudo, e não para adquirir habilidades burocráticas.

É fácil, adicionalmente, entender que essa contradição - pesquisador inovador e competente versus expert em processos burocráticos - se agudiza como um conflito nas vivências cotidianas do pesquisador, principalmente nas vivências daqueles inseridos nos programas de pós-graduação, porque estão diante da pressão para que produzam mais em pesquisa, publiquem e elevem seus programas a uma projeção internacional. Não se critica aqui tais pressões, que de fato são merecedoras de maior reflexão, mas não no escopo do presente texto. Essas pressões têm no mínimo a legitimidade de exigir a adequada aplicação dos recursos públicos aplicados nos programas de pós-graduação e estão relacionadas com as políticas de ciência e tecnologia do País. Dessa forma, o que se deseja registrar é que a burocratização da ciência contradiz os interesses nacionais de avanço em ciência e tecnologia. Monteiro afirma que é "necessário que o pesquisador não perceba o fluxo de avaliações dos projetos pelos CEPs somente como uma burocracia" (2007, p. 89). Essa afirmação é corroborada pela análise de Padilha et al. na Enfermagem, em que a atitude de banalização da ética pelos pesquisadores posta em tal contexto de pressões contraditórias pode ser compreendida como uma forma de reagir, que procura meios viáveis de sobrevivência acadêmica.

Um desdobramento da burocratização da ética é alimentar o descrédito em relação a qualquer possibilidade de controle social sobre 
as condutas em seus aspectos éticos e morais na produção da ciência e da tecnologia, como é o caso da linha de argumentação de Silveira e Hüning, que entendem que os Comitês de Ética são instâncias burocráticas condenadas necessariamente à lentidão e à ineficiência. Afirmam, então:

A constituição de uma democracia ética nas universidades e na sociedade brasileira passa pela dissolução dos comitês de ética e pela responsabilização de cada uma das pessoas que fazem parte do processo de pesquisa: somos nós os responsáveis pelas nossas ações e pelas ações de nossos colegas" (Silveira \& Hüning, s/d)

Embora seja interpretada como equivocada essa linha de argumentação, que retrocede aos anos 80, compreende-se que ela é alimentada e ganhará cada vez mais força, se as práticas sociais dos comitês continuarem se perdendo no detalhamento normativo e tornando cada detalhe um valor em si, cristalizado, independente da ética que o fundamenta. É preciso encontrar um caminho em que se possa harmonizar o cuidado e a reflexão ética e moral com o estímulo ao progresso técnicocientífico. A proteção da autonomia e dos direitos do sujeito participante como valor ético não deve ser excludente do valor igualmente ético da inovação e do progresso científico. A tendência que torna tais princípios excludentes certamente tem, por trás, a pressa de aderir ao novo, traço cultural, sem nenhuma dúvida, forte na contemporaneidade.

Por fim, menciona-se aqui o problema dos grupos de participantes considerados vulneráveis, especialmente crianças e adolescentes, para os quais a Resolução do CNS leva a se exigir que os pais ou os responsáveis assinem o TCLE. Se esses sujeitos são abordados na escola, qual o impedimento de esta última ter a opção de assumir a autorização, principalmente quando as pesquisas consistem apenas na aplicação de questionários, testes ou entrevistas? Será que os professores, no cotidiano da escola, não assumem muito mais pelos seus alunos? Tal procedimento na pesquisa não desvaloriza o papel do professor e dos dirigentes das escolas?

\section{Sinalizando caminhos por uma ética nas pesquisas em Psicologia}

Tudo isso exposto, espera-se que tenha ficado clara a existência das seguintes contradições decorrentes da normatização ética e moral em construção no País:

O PL em trâmite e a Resolução do CNS guardam contradições referentes ao âmbito de aplicação das normas para todas as pesquisas com seres humanos versus para pesquisas clínicas e/ou em saúde com método experimental;

O TCLE, dependendo do tema da pesquisa, ora favorece o princípio de preservação da autonomia do participante, ora o expõe inadequadamente perante as relações de poder em que está implicado;

O excesso de detalhamento e a redundância do texto da Resolução impõem ao pesquisador brasileiro, frente às suas condições de trabalho, um conflito entre seu papel de pesquisador e o de expert em elaboração de processos burocráticos;

A burocratização da ciência promovida pela Resolução se contrapõe aos interesses de avanço nacional em ciência e tecnologia.

Assim, a análise dos documentos leva a reconhecer a necessidade de se implementar alternativas de ação para enfrentar o problema. As alternativas vislumbradas consistem basicamente em optar por contribuir para 
a construção de um substitutivo de lei elaborado de maneira a ser adequadamente aplicável a quaisquer pesquisas que envolvam seres humanos ou a restringir tal projeto a um âmbito mais específico.

Ambas, sem dúvida, parecem legítimas e têm potencial para equalizar melhor os conflitos que se vive em referência à ética em pesquisa atualmente. Entretanto, deliberadamente aderindo à compreensão de que as atividades de pesquisa são práticas sociais como quaisquer outras, principalmente quando se utilizam recursos públicos, reconhece-se a necessidade de se primar pela transparência e de se submeter à avaliação dos pares em seus aspectos éticos e morais. Sugere-se, então, que se assuma a primeira opção e que se ponha em prática as seguintes ações:

Desenvolver mobilização a fim de preparar sugestões objetivas para a construção do substitutivo ao Projeto de Lei;

Defender um projeto de lei mais focado no plano ético e menos no plano moral;

Propor a simplificação do protocolo de pesquisa, permitindo que os projetos tenham diferentes formatos de acordo com a área do conhecimento, o objeto de pesquisa, a abordagem do pesquisador e os métodos e as técnicas utilizadas, eliminando a solicitação de documentos redundantes e a obrigatoriedade de itens que não fazem sentido para todas as pesquisas;

Simplificar a descrição do TCLE, evitando exigir informações redundantes;

Especificar os casos em que o TCLE é obrigatório e habilitar os CEPs a dispensálo sempre que se ponha em contradição quanto à proteção do sujeito participante da pesquisa, bem como flexibilizá-lo tendo em vista a diversidade paradigmática, teórica e metodológica das pesquisas;

Flexibilizar a composição dos CEPs para que possam ser organizados de modo a focalizar uma área de conhecimento, o que provavelmente tornará os CEPs mais competentes na matéria dos projetos que avaliam e que poderá levar em conta os procedimentos morais que tradicionalmente são aplicados pelos pesquisadores em conformidade com a área de conhecimento;

Retirar o Capítulo III do projeto de lei em trâmite, referente aos crimes e às penas;

Constituir comissão que tenha o encargo de redigir as contribuições para a elaboração do substitutivo.

Por fim, registra-se aqui a expectativa de que se possa superar em breve essa fase de discussão da ética em pesquisa em seus aspectos burocráticos, que desloca o foco para o plano moral, e de que se viabilize de fato o avanço de uma discussão mais profundamente ética, que ponha em pauta as definições acerca de que ciência e tecnologias planejam construir, que impactos devem ter nas vidas das pessoas e da sociedade, a quem deve servir a ciência e o que se define como pesquisas relevantes. Isso não significa que se abandone o plano moral, pois o plano ético não se concretiza sem estar relacionado harmoniosamente com o plano moral. 


\section{Livia de Oliveira Borges}

Doutora em Psicologia pela Universidade de Brasília e professora da Universidade Federal de Minas Gerais,

Belo Horizonte $-M G$ - Brasil.

E-mail: liviadeoliveira@gmail.com

\section{Sabrina Cavalcanti Barros}

Mestre em Psicologia pela Universidade Federal de Minas Gerais, Belo Horizonte - MG - Brasil.

E-mail: sabrina.psic@gmail.com

\section{Clara Pires do Rêgo Lobão Amorim Leite}

Mestre em Psicologia pela Universidade Federal de Minas Gerais, Belo Horizonte - MG - Brasil.

E-mail: claralobao@hotmail.com

Endereço para envio de correspondência:

Rua Dr. Sylvio Manicucci, 131, ap. 101, Bairro Castelo. CEP: 30840-480. Belo Horizonte, MG

Recebido 28/07/2011, 1a Reformulação 22/10/2012, Aprovado 29/11/2012.

\section{Referências}

Aguirre, A. M. B. (2008). O termo de consentimento livre e esclarecido: desafios e dificuldades em sua elaboração. In I. C. Z. Gurriero, M. L. S. Schmidt \& F. Zicker (Orgs.). Éticas nas pesquisas em ciências humanas e sociais na saúde (pp. 206-222). São Paulo: Hucitec.

Amazarray, M. R. (2010). Violência psicológica e assédio moral no trabalho enquanto expressões de estratégias de gestão. Tese de doutorado. Universidade Federal do Rio Grande do Sul, Porto Alegre, RS.

Borges, L. O., \& Barbosa, S. B. (2006). Aspectos psicossociais do trabalho dos petroleiros. Dois estudos empíricos no Rio Grande do Norte. Natal: EDURFN, RN.

Bucher-Maluschke, J. S. N. F. (2006). Ética e responsabilidade na pesquisa em Psicologia. Revista Humanidades, 21(1), 7-10.

Calvetti, P. U., Fighera, J., \& Muller, M. C. (2008). A bioética nas intervenções em psicologia da saúde. Psic, 9(1), 115-120.

Conselho Nacional de Saúde (CNS). (1996). Resolução $n^{\circ}$ 196/96, Brasília, DF.

Dallari, S. G. (2008). A proteção do direito à intimidade, à confidencialidade e o sigilo na pesquisa em saúde. In I. C.
Z. Guerriero, M. L. S. Schmidt \& F. Zicker (Orgs.). Éticas nas pesquisas em ciências humanas e sociais na saúde (pp. 53-82). São Paulo: Hucitec.

Fórum de Ética em Pesquisa da ANPEPP. (2012). Relatório do Fórum de Ética. XIV Simpósio da ANPEPP, Belo Horizonte. Recuperado em 30 ago., 2012, de http://www.anpepp. org.br/5-5-Comissoes/Comis-etica/ComissaoXIVSimposio/ relatorio $\% 20$ comissao $\% 20$ etica $\% 20 \% 20$ forum $\% 20$ final .pdf)

Goulart, I. B. (2002). Estudos exploratórios em psicologia organizacional e do trabalho. In I. B. Goulart (Org.). Psicologia organizacional e do trabalho: teoria, pesquisa e temas correlatos (pp. 159-183). São Paulo: Casa do Psicólogo.

Guerriero, I. C. Z. (2006). Aspectos éticos das pesquisas qualitativas em saúde. Tese do doutorado. Universidade de São Paulo, São Paulo, SP.

Guerriero, I. C. Z. (2008). O papel do comitê de ética em pesquisa na Secretaria Municipal de Saúde de São Paulo. In I. C. Z. Guerriero, M. L. S. Schmidt \& F. Zicker (Orgs.). Éticas nas pesquisas em ciências humanas e sociais na saúde (pp. 253-267). São Paulo: Hucitec.

Guerriero, I. C. Z., \& Dallari, S. G. (2008). A necessidade de 
diretrizes éticas adequadas às pesquisas qualitativas em saúde. Ciência \& Saúde Coletiva, 13(2), 303-311.

Koller, S. H. (2008). Ética com seres humanos: alguns tópicos sobre a psicologia. Ciência \& Saúde Coletiva, 13(2), 399-406.

La Taille, Y. (2006). Moral e ética. Dimensões intelectuais e afetivas. Porto Alegre: Artmed.

La Taille, Y. (2010). Ética em pesquisa com seres humanos: dignidade e liberdade (texto completo). In Associação Nacional de Pesquisa e Pós-graduação em Psicologia. XIII Simpósio de Pesquisa e Intercâmbio Científico (pp.198-204). Fortaleza, CE: ANPEPP.

Leitão, S. (2010). Marcos na reflexão da ANPEPP sobre a ética em pesquisa com seres humanos (texto completo). In Associação Nacional de Pesquisa e Pós-graduação em Psicologia. XIII Simpósio de Pesquisa e Intercâmbio Científico (pp. 205-208). Fortaleza, CE: ANPEPP.

Menegon, V. S. M. (2006). Entre a linguagem do direito e a linguagem do risco. Os consentimentos informados na reprodução humana assistida. São Paulo: EDUC.

Minayo, M. C. S. (2008). Contribuições da antropologia para dilemas éticos da área de saúde. Ciência \& Saúde Coletiva, 13(2), 329-339.

Monteiro, K. C. C. (2007). O consentimento informado na pesquisa em psicologia hospitalar. Epistemo-somática, 4(1), 84-92.

Mueller, M. R., \& Instone, S. (2008). Beyond the informed consent procedure: Continuing consent in human research. Ciência \& Saúde Coletiva, 13(2), 381-389.

Padilha, M. I. C. S., Ramos, F. R. S., Borenstein, M. S., \& Martins, C. R. (2005). A responsabilidade do pesquisador ou sobre o que dizemos acerca da ética em pesquisa. Texto Contextoenfermagem, 14(1), 96-105.

Piovesan, A., \& Temporini, E. R. (1995). Pesquisa exploratória: procedimento metodológico para o estudo de fatores humanos no campo da saúde pública. Revista de Saúde Pública, 29(40), 318-325. Recuperado em 23 jul., 2011, de http://www.scielo.br/pdf/rsp/v29n4/10.pdf

Senado Federal. (2006). Projeto de Lei $\mathrm{n}^{\circ} 78 / 2006$. Recuperado em 29 set., 2012, de http://www6.senado.gov.br/matepdf/7891.pdf

Ribeiro, C. R. O. (2005). Ética e pesquisa em álcool e drogas: uma abordagem bioética. Revista Eletrônica Saúde Mental Álcool e Drogas, 1(1). Recuperado em 29 abr., 2010, de http://pepsic. bvs-psi.org.br/scielo.php?script $=$ sci_arttext\&pid $=$ S1677$11682006000100008 \& \operatorname{lng}=$ pt\&nrm $=$ iso

Rios, T. A. (2006). A ética na pesquisa e a epistemologia do pesquisador. Psicologia em Revista, 12(19), 80-86. Recuperado em 30 abr., 2011, de World Wide Web: http://pepsic. bvs-psi.org.br/scielo. php?script $=$ sci_arttext\&pid $=$ S1677$11682006000100008 \& \operatorname{lng}=$ pt\&nrm $=$ iso.

Schmidt, M. L. S. (2008a). Aspectos éticos nas pesquisas qualitativas. In I. C. Z. Guerriero, M. L. S. Schmidt \& F. Zicker (Orgs.). Éticas nas pesquisas em ciências humanas e sociais na saúde (pp. 247-252). São Paulo: Hucitec.

Schmidt, M. L. S. (2008b). Pesquisa participante e formação ética do pesquisador na área da saúde. Ciência \& Saúde Coletiva, 13(2), 391-398.

Schramm, F. R., Palácios, M., Rego, S. (2008). O modelo bioético principialista para a análise da moralidade da pesquisa científica envolvendo seres humanos ainda é pesquisa científica envolvendo seres humanos é satisfatório? Ciência \& Saúde Coletiva, 13(2), 361-370.

Schwartz, S. (2005). Valores humanos básicos: seu contexto e estrutura intercultural. In A. Tamayo \& J. B. Porto (Orgs.). Valores e comportamento nas organizações (pp. 21-55). Petrópolis, RJ: Vozes.

Secretaria Municipal de Saúde de São Paulo (2007). Reunião sobre Ética em Pesquisa Qualitativa em Saúde. Relatório. São Paulo, SP.

Senado Federal. Portal da Atividade Legislativa. PLS Projeto de Lei $\mathrm{n}^{\circ}$ 78, de 2006. Recuperado em 29 abr., 2010, de http://www.senado.gov.br/atividade/materia/detalhes. asp?p_cod_mate $=77271$.

Silva, M. P. C., \& Grubits, S. (2006). Reflexões éticas em pesquisas com populações indígenas. Psicologia: Ciência e Profissão, 26(1), 46-57.

Silveira, R. A. T., \& Hüning, S. M. (s/d). A tutela moral dos comitês de ética. Apresentado no XV Encontro Nacional da Associação Brasileira de Psicologia Social. Maceió: ABRAPSO.

Sociedade Brasileira para o Progresso da Ciência (SBPC) (2010, 16 de abril). Pesquisas com seres humanos: projeto de lei ainda em debate. Jornal da ciência, 664, p. 2, Recuperado em 26 de jan. de 2012 de http://www.jornaldaciencia.org.br/ Detalhe.jsp?id=70323)

Trindade, Z. A., \& Szymanski, H. (2008). O impacto dos comitês de ética - CEPs na atividade de pesquisa em psicologia. In I. C. Z. Gurriero, M. L. S. Schmidt \& F. Zicker (Orgs.). Éticas nas pesquisas em ciências humanas e sociais na saúde (pp. 280302). São Paulo: Hucitec.

Tripodi, T. (1975). Análise da pesquisa social. Rio de Janeiro: F. Alves.

Wainer, R. (2000). A pesquisa quantitativa em psicologia delineamentos e a questão da amostragem. In H. Scarparo (Org.). Psicologia e pesquisa: perspectivas metodológicas (pp. 17-34). Porto Alegre: Sulina. 